\title{
Outcomes of Pregnancies Complicated by Maternal Tuberous Sclerosis
}

\author{
Laura Bonebrake, MD¹, Karishma Rai, MD¹, Jerome Yankowitz, MD
}

Keywords: pregnancy, tuberous sclerosis

\section{Objective}

To determine the outcomes of pregnancies complicated by maternal tuberous sclerosis.

\section{Background}

Tuberous sclerosis (TS) is a genetic disorder that is inherited in an autosomal dominant fashion with variable clinical manifestations including seizures, mental retardation, renal failure and pneumothorax. The literature on TS in pregnancy is largely based upon case reports which have shown a $43 \%$ complication rate including oligohydramnios, polyhydramnios, IUGR, hemorrhage from ruptured renal tumors, PPROM, renal failure, placental abruption and perinatal demise.

${ }^{1}$ Department of Obstetrics and Gynecology, Carver College of Medicine, University of lowa Hospitals and Clinics, lowa City, IA, 52242

\section{Methods}

Retrospective chart review of female patients with tuberous sclerosis older than 18 years treated at our hospital. Pregnancy records were then obtained after consent consistent with IRB approval. Charts were reviewed for pre-pregnancy manifestations of tuberous sclerosis, pregnancy outcomes, and fetal ultrasound manifestations.

\section{Results}

Consent forms were mailed to 27 prospective subjects. Eight forms were returned. Full pregnancy records were obtained on 2 subjects with partial records from a third patient. Patient \#1 had brain tubers without epilepsy and multiple angiomyolipomas of the kidneys. She had normal renal function throughout pregnancy. Her pregnancy was complicated by oligohydramnios at 38 weeks gestation. Delivery was by cesarean section at 39 weeks gestation of a 2922 gram infant after failure to descend. There were no maternal

Please cite this paper as: Bonebrake L, Rai K, Yankowitz J. Outcomes of pregnancies complicated by maternal tuberous sclerosis. Proc Obstet Gynecol. 2012;2(3):Article 3 [2 p.]. Available from: http://ir.uiowa.edu/pog/. Free full text article.

Corresponding author: Donna Santillan, Department of Obstetrics and Gynecology, University of lowa, 463 MRF, 200 Hawkins Drive, lowa City, IA 42242. donna-santillan@uiowa.edu. 
complications of the pregnancy. Patient \#2 had brain tubers without epilepsy. She had an uncomplicated pregnancy and delivered a 2980 gram infant at $38 \quad 4 / 7$ weeks gestation. Neither of these patients had fetal manifestations of tuberous sclerosis identified on ultrasound. Patient \#3 had brain tubers and absence seizures. Her pregnancy was complicated by fetal rhabdomyomas. She was lost to follow up after 36 weeks of gestation but her pregnancy was otherwise uncomplicated to this point. Nineteen patients did not return consent forms. They had been seen in our hospital for fetal ultrasound or pediatric genetics and continued to be followed by their local obstetricians. We extrapolate from this that their pregnancies were uncomplicated as our university is the main referral center for the area. We do not have confirmation per prenatal records.

\section{Conclusions}

We present three cases of maternal tuberous sclerosis without major complications in pregnancy. Several other patients delivered with a low risk obstetrician and we conclude from this that maternal tuberous sclerosis may not be as high risk for pregnancy as previously reported in the literature. This case series can aid obstetricians in counseling of patients with this rare disorder. 